\title{
Formation of a given variable structure in detail by means of selective laser melting technologya
}

\author{
Evgeny Borisov ${ }^{*}$, Dmitry Masailo ${ }^{1}$, Igor Polozov ${ }^{1}$, and Vera Popovich ${ }^{2}$ \\ ${ }^{1}$ National Technological Initiative Center "New Production Technologies", Peter the Great St. \\ Petersburg Polytechnic University, 195251, Polytechnicheskaya st., 29, Russian Federation \\ ${ }^{2}$ Delft University of Technology, Mekelweg 2, 2628 CD Delft, Netherlands
}

\begin{abstract}
The issue for creation of products with functional properties adapted to working conditions is currently vital. The possibility of creating local areas with a specified microstructure and properties in the product is of special interest. This work covers the performed study of the structure and properties of the heat-resistant nickel alloy Inconel 718, depending on the process parameters used. The possibility for combination of different process modes during manufacture of one product to obtain its variable structure is shown. The specimens with areas of small equiaxed and large elongated grains were studied. The carried out EBSD analysis showed that the local change in the size and morphology of the material grain is possible by changing the layer thickness and process parameters of the selective laser melting process. It is shown that after the heat treatment and hot isostatic pressing, the differences in the structure and mechanical properties between the areas remain.
\end{abstract}

\section{Introduction}

In recent decades, a qualitative change in the nature of products manufactured by modern industry has taken place. Especially it concerns machine building, aviation, space industries, medicine (for example, in terms of implants manufacture), etc. The transition from manual design to digital, implementation of information technologies into the life cycles of products, automation of production processes contribute to formation of a new industrial base that will become the basis in case the future economy structure is formed.

One of the most important technologies to implement this concept is additive technologies. The additive technologies are of great interest for manufacturing metal products, as they allow creating complex-surface structures with increased mechanical characteristics.

Among the additive technologies, the selective laser melting (SLP) is currently considered as one of the most prospective for the manufacture of metal parts $[1,2]$. The

\footnotetext{
${ }^{a}$ The work was carried out in the framework of the implementation of the federal target program "Study and development in priority aspects of development of Russian scientific and technological sector for 2014-2020", the unique identifier of the project is RFMEFI57817X0245.

* Corresponding author: evgenii.borisov@icloud.com
} 
selective laser melting technology is already actively used for manufacturing metal products that relates to the possibility of manufacturing blanks which are as close to the final product as possible in terms of the geometry. The latter is especially vital in such areas as aviation and medicine [3-5]. In aviation, where titanium and nickel alloys are widely used, special requirements for products weight are used. The use of additive technologies makes it possible to create parts with a geometry that ensures the structure simplicity while maintaining high strength characteristics [6].

Among the nickel super-alloys, Inconel 718 attracts much attention of researchers due to its wide application in gas turbine components, aerospace unit parts, in petrochemical and nuclear industries thanks to its heat-, corrosion-resistant and high-temperature properties [4]. Traditionally, the parts are manufactured from this alloy by forging, rolling and casting. However, the modern industry development requires the production of products of complex shapes with high accuracy and high mechanical properties that sometimes are impossible to provide by conventional production methods.

In the literature, the works are used to study the selective laser melting process of Inconel 718 alloy, where the parameters impact on the relative density is considered, but, as a rule, they focus only on the laser power and the speed of its displacement, while remaining other values $[7,8]$. To control the technical process, it is necessary to understand the influence patterns of one or another parameter on the final result. However, small data has been published on the possibility to use the features of the selective laser melting process to control the crystallographic texture and microstructure dispersion, and smaller data on the relationship between the preferred anisotropy, microstructure and mechanical properties of the alloy. In this regard, the purpose of this work is to establish patterns of structure formation depending on the initial process parameters and to develop a manufacturing method, and to study the properties of compact products with variable structure.

\section{Materials and methods for research}

Compact specimens were made on selective laser melting unit SLM280HL, manufactured by SLM Solutions GmbH. A powder of heat-resistant nickel alloy Inconel 718 obtained by gas atomization method was used as a basic material. The measured chemical composition of the alloy Inconel 718 powder is given in Table 1.

Table 1. Chemical composition of Inconel 718 powder particles (measured by energy dispersive spectroscopy)

\begin{tabular}{|l|l|l|l|l|l|l|l|l|l|}
\hline Element & $\mathrm{Ni}$ & $\mathrm{Cr}$ & $\mathrm{Fe}$ & $\mathrm{Nb}$ & $\mathrm{Mo}$ & $\mathrm{Ti}$ & $\mathrm{Al}$ & $\mathrm{Co}$ & $\mathrm{Mn}$ \\
\hline Content, mass \% & 51.4 & 19.4 & 18.5 & 5.3 & 3.4 & 1.0 & 0.7 & 0.1 & 0.1 \\
\hline
\end{tabular}

Particle distribution in sizes was determined using a laser diffraction method with instrument Analysette 22 NanoTecPlus with a full scale range of 0.01-2000 $\mu \mathrm{m}$. A flow rate of powder was evaluated using a hall flowmeter. Surface morphology, microstructure of particles and compact specimens, texture characteristics by electron backscatter diffraction (EBSD) were studied using scanning electron microscope TESCAN Mira 3 LMU (SEM) operated when increasing 4-106 at an accelerating voltage of $200 \mathrm{~V}-30 \mathrm{kV}$, the EBSD analysis was carried out at accelerating voltage of $20 \mathrm{kV}$ at a pitch of $5 \mu \mathrm{m}$. The X-ray phase analysis was performed with multifunctional X-ray diffractometer Bruker D8 Advance. To determine the mechanical properties, the tests were carried out in accordance with ISO 6892-1 using test machine Zwick / Roell Z100 (Germany) with a maximum force of $99640 \mathrm{~N}$. The relative density was measured using the metallographic method and hydrostatic weighing. The hot isostatic pressing (HIP) was carried out in gasostatic extruder Avure Quintus at a temperature 
of $1180{ }^{\circ} \mathrm{C}$ and a pressure of $150 \mathrm{MPa}$ for 3 hours. The heat treatment was carried out in two stages: annealing at a temperature of $1065{ }^{\circ} \mathrm{C}$ for 1 hour with cooling in the air; aging was carried out in two stages, 1 - at a temperature of $760{ }^{\circ} \mathrm{C}$ for 10 hours, then cooling to $650{ }^{\circ} \mathrm{C}$ for 2 hours and curing at $650{ }^{\circ} \mathrm{C}$ for 8 hours, then cooling in the air.

\section{Results of the work and their discussion}

\subsection{Study of basic material}

Studies of the Inconel 718 powder with the scanning electron microscope (Fig. 1) showed that the powder particles have a round, nearly spherical shape. Some of the particles have growth-satellite (Fig. 1, a). These growths can affect the obtained filling density both by its increasing by filling small pores if they break away from large particles and by its reducing by preventing compaction if they are firmly fixed on the main particles. As well as these growths can affect the powder process properties, such as flow rate, degree of laser radiation absorption, etc. The studies of the particles surface morphology at high magnification showed that their surfaces have some irregularities reflecting the material cast microstructure and refer to cellular-dendritical crystallization (Fig. 1, b) [9]. From the results of the granulometric composition measurement, it is seen that the predominant particle size is about $37 \mu \mathrm{m}$. The difference is not very large; the sizes of more than $90 \%$ of the particles are within the range of 20 to $62 \mu \mathrm{m}$.

a)

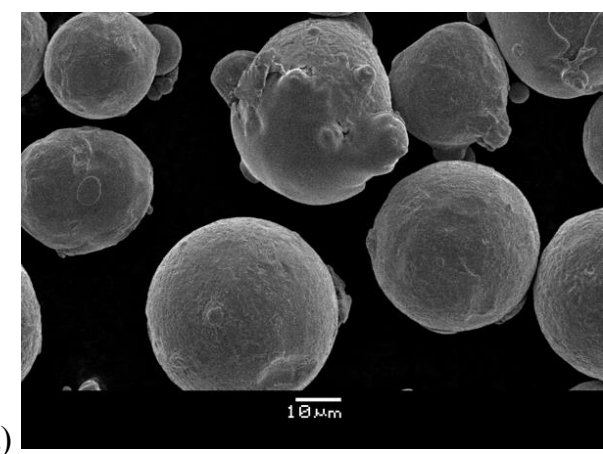

b)

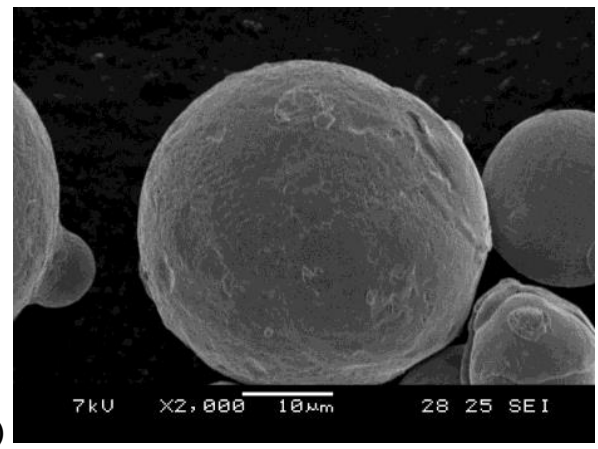

Fig. 1. SEM-images of super-alloy Inconel 718 particles obtained by gas atomization method.

\subsection{Manufacture of specimens by selective laser melting}

To obtain specimens for studying the microstructure, phase composition, and mechanical properties, the modes for layer thicknesses of 30, 50 and $100 \mu \mathrm{m}$ were used. Due to rapid solidification during the SLM process $\left(10^{4}-10^{6} \mathrm{~K} / \mathrm{s}\right)$, the initial microstructure consists of cellular dendrites. A solidification rate and the cells size, respectively, depend on the layer thickness and the process parameters used in the SLM.

It has been established that such parameters as a laser beam moving speed, its power and the distance between the individual passages have a greater effect on the specimens' porosity than on the structure parameters. Change in the construction layer thickness simultaneously with the change in the diameter of the laser spot makes it possible to significantly change the characteristics of the directed structure (Fig. 2). It is possible to obtain either a fine- or coarsegrained directed structure. The measurements showed that the average cell size at a layer thickness of $30 \mu \mathrm{m}$ is $0.7-0.9 \mu \mathrm{m}$, at $50 \mu \mathrm{m}$ it is $0.9-1.1 \mu \mathrm{m}$, and at $100 \mu \mathrm{m}$ it is $1.3-2 \mu \mathrm{m}$. 
a)

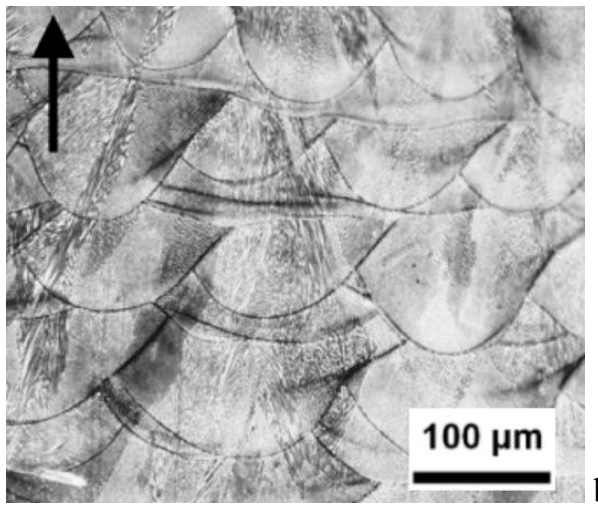

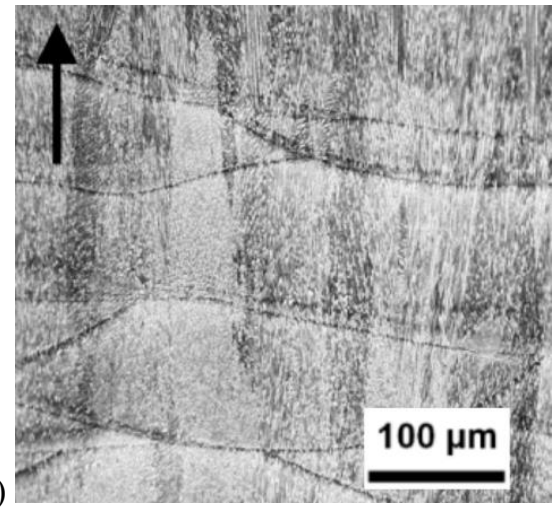

Fig. 2. The microstructure of specimens obtained by the SLM method using a layer thickness of 50 $\mu \mathrm{m}$ (a) and $100 \mu \mathrm{m}$ (b)

Other differences in the microstructure formation with different layers thicknesses are shown in Fig. 3, where a texture study performed by the EBSD analysis is presented. The microstructure of the specimen made with a layer thickness of $50 \mu \mathrm{m}$ has finely dispersed grains without a predominant orientation, whereas the microstructure of the specimen made at a layer thickness of $100 \mu \mathrm{m}$ has columnar grains with a predominant orientation $<001>$.

Differences in the microstructure shall also affect the strength characteristics. To perform the rupture test, cylindrical specimens were prepared for testing in accordance with ISO 6892-1. The specimen yield strength, ultimate stress and elongation (given in Table 2) were determined from the tensile test results.

a)

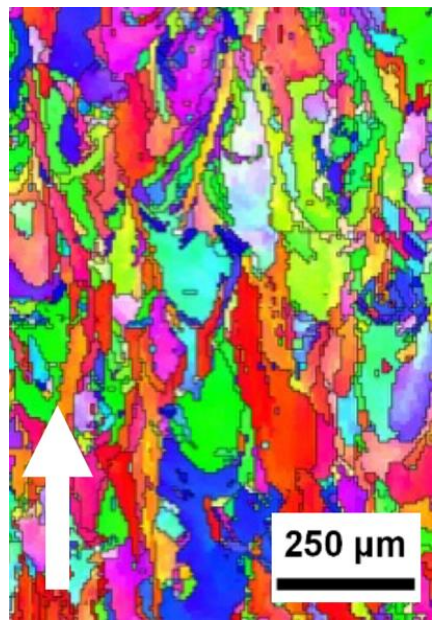



c)

Fig. 3. The EBSD analysis of specimens made by SLM: a) crystal grains orientation map for a specimen with a layer thickness of $50 \mu \mathrm{m}$; b) crystal grains orientation map for a specimen with a layer thickness of $100 \mu \mathrm{m}$; c) an index map for figures a) and b). The specimens' growth orientation is indicated by arrow. 
Table 2. The results of tensile tests of specimens of alloy Inconel 718 made by SLM method.

\begin{tabular}{|c|c|c|c|}
\hline $\begin{array}{c}\text { Layer } \\
\text { thickness, } \boldsymbol{\mu m}\end{array}$ & Yield strength, MPa & Ultimate strength, MPa & $\begin{array}{c}\text { Percentage of elongation, } \\
\%\end{array}$ \\
\hline \multicolumn{3}{|c|}{ Selective laser melting } \\
\hline 30 & $745 \pm 9$ & $1004 \pm 8$ & $25 \pm 3$ \\
\hline 50 & $650 \pm 11$ & $845 \pm 9$ & $28 \pm 4$ \\
\hline 100 & $543 \pm 2$ & $782 \pm 6$ & $31 \pm 6$ \\
\hline \multicolumn{5}{|c|}{ Selective laser melting + hot isostatic pressing } \\
\hline 50 & $645 \pm 6$ & $1025 \pm 14$ & $38 \pm 1$ \\
\hline 100 & $481 \pm 11$ & $788 \pm 12$ & $21 \pm 1$ \\
\hline \multicolumn{5}{|c|}{ Selective laser melting + hot isostatic pressing + } \\
\hline 30 & $1157 \pm 8$ & $1363 \pm 12$ & $19 \pm 1$ \\
\hline 50 & $1145 \pm 16$ & $1376 \pm 14$ & 11 \\
\hline 100 & $1065 \pm 20$ & $1272 \pm 12$ & 24 \\
\hline $\begin{array}{c}\text { Cast [10] } \\
\text { Hot rolling, } \\
\text { grain is about } \\
40 \mu \mathrm{m}[11]\end{array}$ & 488 & 786 & 24 \\
\hline $\begin{array}{c}\text { Hot rolling, } \\
\text { grain is about } \\
100 \mu \mathrm{m}[11]\end{array}$ & 1245 & 1415 & \\
\hline
\end{tabular}

After annealing and aging, the mechanical properties have significantly higher values (see Table 2), this was due to changes in the material phase composition, separation of strengthening phase $\gamma$ "-Ni3 Nb. Mechanical properties after HIP decreased due to grain growth at an increased temperature, but the HIP significantly increased the percentage of elongation.

High-temperature properties are very important for super-alloys; the parts made of Inconel 718 are usually not used for a long time at temperatures over $650{ }^{\circ} \mathrm{C}$. The results of studying the short-term tensile strength of tensile specimens before and after heat treatment and HIP carried out at $650{ }^{\circ} \mathrm{C}$ according to ISO 6892-2 are given in Table 3.

Table 3. Mechanical properties at $650^{\circ} \mathrm{C}$ of specimens made with SLM and subsequent HIP and thermal treatments

\begin{tabular}{|c|c|c|c|}
\hline $\begin{array}{c}\text { Layer } \\
\text { thickness, } \boldsymbol{\mu m}\end{array}$ & Yield strength, MPa & $\begin{array}{c}\text { Ultimate strength, } \\
\mathbf{M P a}\end{array}$ & $\begin{array}{c}\text { Percentage of elongation, } \\
\mathbf{\%}\end{array}$ \\
\hline \multicolumn{4}{|c|}{ Selective laser melting } \\
\hline 30 & $716 \pm 11$ & $828 \pm 9$ & $27 \pm 4$ \\
\hline 50 & $650 \pm 11$ & $845 \pm 9$ & $28 \pm 4$ \\
\hline 100 & $543 \pm 2$ & $782 \pm 6$ & $31 \pm 6$ \\
\hline \multicolumn{4}{|c|}{ Selective laser melting + hot isostatic pressing } \\
\hline 50 & $626 \pm 8$ & $857 \pm 14$ & $29 \pm 1$ \\
\hline 100 & $479 \pm 5$ & $665 \pm 7$ & $28 \pm 2$ \\
\hline
\end{tabular}




\begin{tabular}{|c|c|c|c|}
\hline $\begin{array}{c}\text { Layer } \\
\text { thickness, } \boldsymbol{\mu m}\end{array}$ & Yield strength, MPa & $\begin{array}{c}\text { Ultimate strength, } \\
\text { MPa }\end{array}$ & $\begin{array}{c}\text { Percentage of elongation, } \\
\%\end{array}$ \\
\hline \multicolumn{4}{|c|}{ Selective laser melting + hot isostatic pressing + } \\
Annealing + Aging \\
\hline 50 & $942 \pm 11$ & $1078 \pm 8$ & $20 \pm 2$ \\
\hline 100 & $872 \pm 13$ & $1005 \pm 12$ & $17 \pm 4$ \\
\hline
\end{tabular}

The results of mechanical tests at the increased temperature showed the stable strength properties with an elongation of about $30 \%$ for the conditions of SLM and SLM+ HIP. The specimens after HIP and subsequent annealing and aging have a lower value of the percentage of elongation, but the higher strength compared to other conditions.

While comparing the results of mechanical tests at the room and elevated temperatures of specimens made with different layer thicknesses and with different post-processing modes, it can be said that the smaller the layer thickness, the higher is the strength.

\subsection{Manufacture of specimens with variable structure}

A method for manufacturing the specimens with the specified structure in individual elements was developed at the next stage of the work. For manufacturing different areas of specimens, the modes for layer thickness values of 50 and $100 \mu \mathrm{m}$ were used. The modes with a larger and smaller layer thickness were used successively in the specimens during the growth process. The specimens EBSD analysis shows (Fig. 4) that there is a mutual penetration of the coarse and fine grains at the boundary, i.e. there is a transition area. Its size is up to 500 $\mu \mathrm{m}$, depending on the relative location of the coarse and fine grains areas.

a)

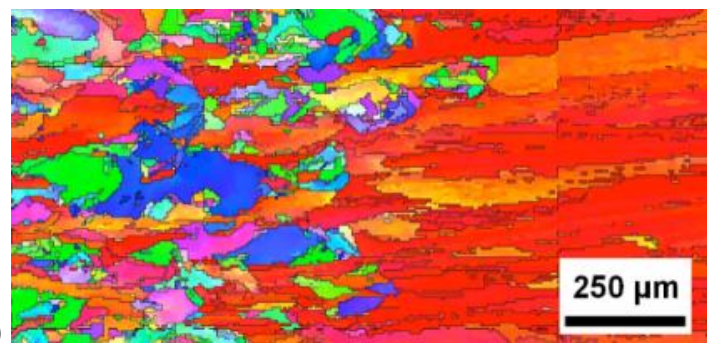

b)

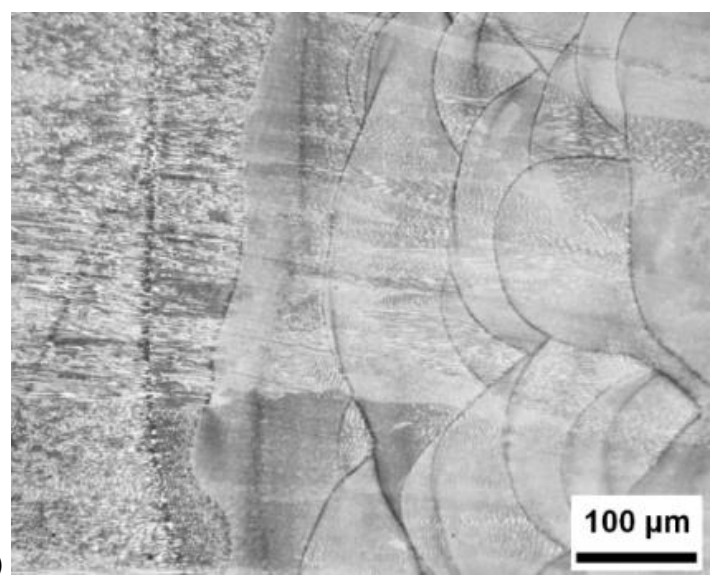

Fig. 4. The variable structure specimens manufacture procedure (a) and EBSD analysis of the transition area of $50 \mu \mathrm{m}-100 \mu \mathrm{m}$ (b). 
High-temperature heating over the recrystallization temperature during hot isostatic pressing resulted in grains coarsening and formation of equiaxed grains in the area made at a layer thickness of $50 \mu \mathrm{m}$ (Fig. 5). Thus, after the heat treatment, two areas are formed: an area of directed columnar grains and a fine-grained equiaxed area.

a)

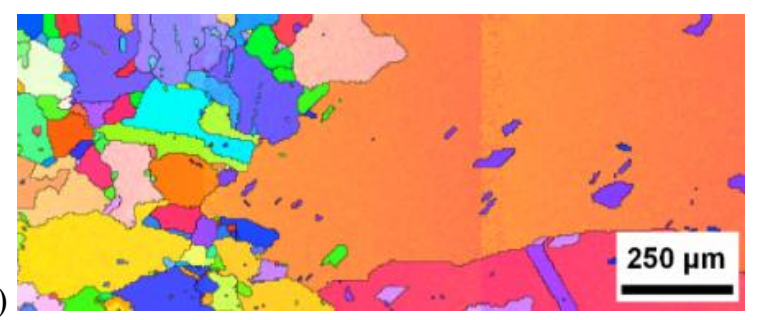

b)

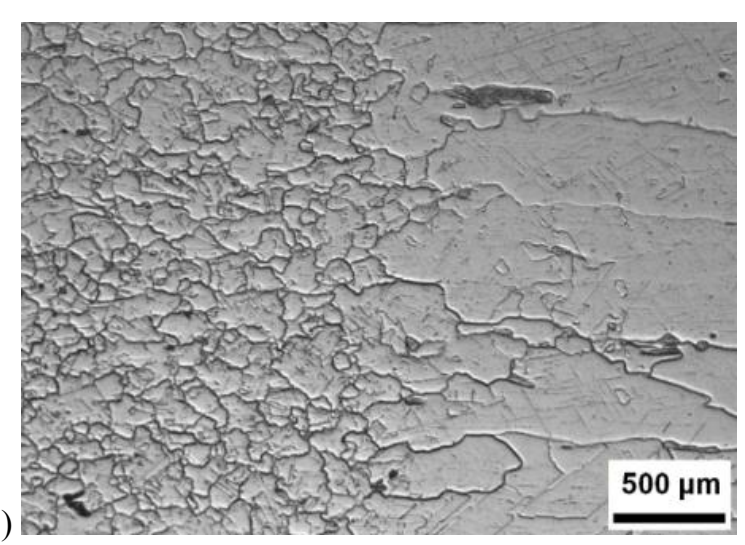

Fig. 5. The microstructure of the boundary area between the sections made at a layer thickness of $50 \mu \mathrm{m}$ (left) and $100 \mu \mathrm{m}$ (right) after SLM+HIP.

The results of measuring a hardness of specimens with variable structure after SLM are shown in Fig. 6.

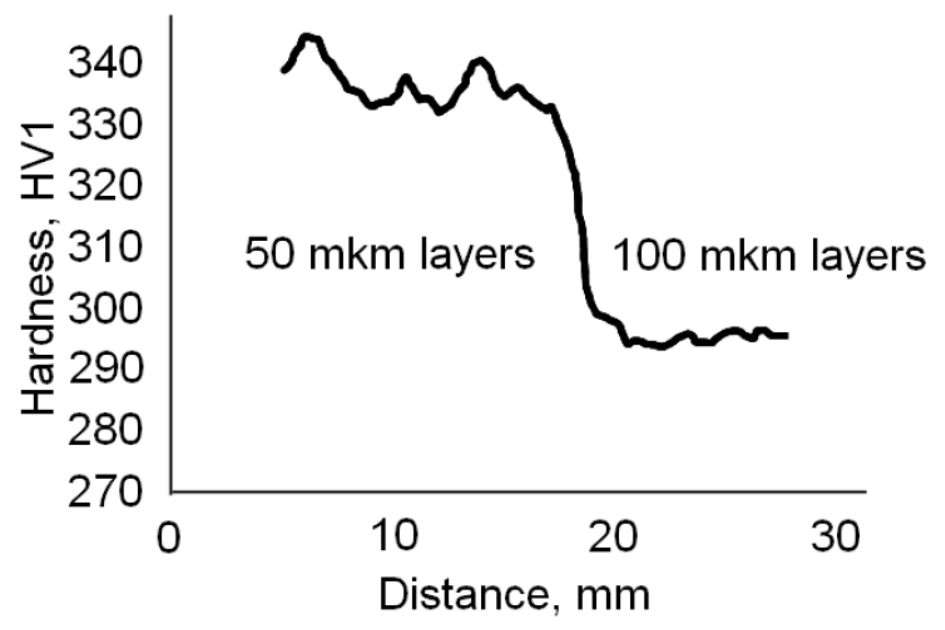

Fig. 6. Hardness of specimens with variable structure. 
The analysis of the change in the hardness of specimens with variable structure showed that a difference in hardness values of about $20 \%$ is observed between the areas, the area of equiaxed fine grains has the higher hardness values.

\section{Conclusions}

The study for the process of selective laser melting of Inconel 718 powder is presented. It was shown that the greater is the layer thickness, the greater is the size of the dendritical cells in the structure, the EBSD analysis showed that the change in the layer thickness and process parameters leads to the change in the grains microstructure, as well as that using the large layer thickness, it is possible to implement the directional solidification mode with formation of columnar grains. The specimens' mechanical properties have a strong dependence on the layer thickness, the thinner is the layer, the higher is the strength of the specimens. The results of studying the microstructure of compact specimens made with alternating areas with coarse and fine grains are presented, and hardness measurements showed the change in the local mechanical characteristics. Based on the performed studies the concept for manufacturing products with the specified microstructure has been formed.

\section{References}

1. M. J. Holzweissig, et al. Metallurgical and Materials Transactions B. 46(2) (2015)

2. A. Popovich, V. Sufiiarov, New Trends in 3D Printing, (InTech, 2016) DOI: $10.5772 / 63337$

3. V. S. Sufiiarov, A. A. Popovich, E. V. Borisov, I. A. Polozov, Non-ferrous metals. 1 (2015)

4. D. F. Paulonis, J. J. Schirra, Superalloys. 718(625,706) (2001)

5. A. K. Abraham, V. G. Sridhar, Trends in Biomaterials \& Artificial Organs. 29(3) (2015)

6. W. E. Frazier, Journal of Materials Engineering and Performance. 23(6) (2014)

7. K. N. Amato, et al. Acta Materialia. 60(5) (2012)

8. Q. Jia, D. Gu, Journal of Alloys and Compounds. 585 (2014)

9. V. M. Golod, V. S. Sufiiarov, IOP Conference Series: Materials Science and Engineering, 192 (1) (2017) DOI: 10.1088/1757-899X/192/1/012009

10. B. Baufeld, Journal of materials engineering and performance. 21(7) (2012)

11. J. P. Pedron, A. Pineau, Materials science and engineering. 56(2) (1982) 